\title{
Exploring Social Justice, Design, and $\mathrm{HCl}$
}

$\begin{array}{ll}\begin{array}{l}\text { Sarah Fox } \\ \text { Human Centered Design \& } \\ \text { Engineering } \\ \text { University of Washington } \\ \text { sefox@uw.edu }\end{array} & \begin{array}{l}\text { Jill Dimond } \\ \text { Sassafras Tech Collective } \\ \text { jill@sassafras.coop }\end{array} \\ \begin{array}{l}\text { Mariam Asad } \\ \text { School of Literature, Media, \& } \\ \text { Communication }\end{array} & \begin{array}{l}\text { School of Informatics \& Computing } \\ \text { Indiana University - Purdue } \\ \text { University - Indianapolis }\end{array} \\ \begin{array}{l}\text { Georgia Institute of Technology } \\ \text { Isdombro@iupui.edu }\end{array} \\ \begin{array}{l}\text { Katherine Lo } \\ \text { Department of Informatics } \\ \text { University of California, Irvine } \\ \text { kat@kmlo.net }\end{array} & \begin{array}{l}\text { Shaowen Bardzell } \\ \text { Indiana University, Bloomington } \\ \text { selu@indiana.edu }\end{array} \\ & \end{array}$

Permission to make digital or hard copies of part or all of this work for personal or classroom use is granted without fee provided that copies are not made or distributed for profit or commercial advantage and that copies bear this notice and the full citation on the first page. Copyrights for third-party components of this work must be honored. For all other uses, contact the Owner/Author.

Copyright is held by the owner/author(s)

CHI'16 Extended Abstracts, May 07-12, 2016, San Jose, CA, USA

ACM 978-1-4503-4082-3/16/05.

http://dx.doi.org/10.1145/2851581.2856465

\begin{abstract}
The aim of this one-day workshop is to share existing research, discuss common practices, and to develop new strategies and tools for designing for social justice in $\mathrm{HCl}$. This workshop will bring together a set of $\mathrm{HCl}$ scholars, designers, and community members to discuss social justice perspectives on interaction design and technology. We will explore theoretical and methodological approaches in and around $\mathrm{HCl}$ that can help us generatively consider issues of power, privilege, and access in their complexity. We will discuss the challenges associated with taking a justice approach in $\mathrm{HCl}$, looking toward existing practices we find both productive and problematic. This workshop will bridge current gaps in research and practice by developing concrete strategies for both designing and evaluating social change oriented work in $\mathrm{HCl}$, where agendas are made clear and researchers are held accountable for the outcomes of their work by members of their field site and the research community.
\end{abstract}

\section{Author Keywords}

Social justice; design.

\section{ACM Classification Keywords}

K.4.0 Computers in Society: general.

This is the author's manuscript of the article published in final edited form as:

Fox, S., Asad, M., Lo, K., Dimond, J. P., Dombrowski, L. S., \& Bardzell, S. (2016, May). Exploring Social Justice, Design, and HCI. In Proceedings of the 2016 CHI Conference Extended Abstracts on Human Factors in Computing Systems (pp. 3293-3300). ACM. https://doi.org/10.1145/2851581.2856465 


\section{Background}

Over the past several years, the $\mathrm{CHI}$ community has seen an increasing interest in research concerning issues of power, privilege, and access. This work has ranged from the introduction and enactment of feminist modes of inquiry $[2,7,13]$ to analytic frameworks like postcolonial computing $[9,15]$. Within certain interventionist projects, there is an express aim to contribute to social change in some way, like Clarke et al.'s efforts to support photo sharing amongst residents of a women's center [4] and Parker Grimes et al.'s ecological approach to designing for health reflection [11]. We see this as a promising trend to enact change through $\mathrm{HCl}$ design, but we also recognize a need to extend and solidify these discussions in order to ensure that work like this continues and to establish modes of reflection and evaluation appropriate to the complex goals inherent to efforts of this nature.

Looking to expand on this work, we seek to facilitate the conversations necessary to move beyond "design with good intentions" toward design praxis, or reflection and action directed to transform oppressive structures with and by the dispossessed, marginalized, and oppressed. Discussions will focus on strategies and techniques for social justice research, emphasizing the development of community/academic partnerships, our role as interventionists in research sites, and methods for evaluating and iterating on contributions to our various communities. Next we delineate the boundaries of social justice and how $\mathrm{HCl}$ relates to these same concerns.

What is Social J ustice?

As a concept and as demonstrated through socia movements, social justice attends to how individuals experience oppression. This includes the ways in which benefits, burdens, obligations, power, opportunity, and privilege have been equitably (or not) distributed within society and how to make a given context more equitable to various stakeholders given competing needs, goals, and resources. It is beyond the scope of this workshop to fully examine the several millennia worth of western thought on the concept of justice (e.g., Plato, Aristotle, Augustine, Aquinas, Hobbes, Hume, Kant, Mill, Iris Marion Young, Kimberlé Crenshaw, and so on); rather, we briefly outline how key concerns of social justice relate to debates within $\mathrm{HCl}$.

Justice and social justice may be seen as different concepts, but social justice builds on the concept of justice to widen the analytical arena in substantial ways. As a perspective, social justice explicitly takes into account how the historicity, situated context, and social issues (e.g., class, race, gender, ability, sexual orientation, health and wellness, food access, and so on) impact people's experiences (e.g. $[1,5,6,16]$ ), including how technology is designed and developed, how policy impacts information and communication practices and experiences, and how marginalization and oppression impact people's experiences of and practices with technology.

At its core, justice focuses on the social concerns, obligations, and ethical commitments created through our interactions with each other. There are many different types of justice, and no single, agreed-upon definition, nor a consensus on how to work towards it, or to verify its achievement. This plurality aligns with current key debates within our discipline and research $[2,8]$, including questions about reflexivity in processes 
of research and design, deployment, and evaluation, which we seek to explore in this workshop.

How does $\mathrm{HCl}$ orient to [or engage with] social justice? Recent efforts, like that of design researchers Smyth and Dimond with the Anti-Oppressive Design Framework [14], have made important moves toward establishing means for designers to reflexively pose questions about their own practice and how it engages systems of oppression. Likewise, in taking up the topic of critical and speculative design, designers and critics Prado and Oliveira have aptly pointed out that many projects produced under its banner present dystopic near futures that actually resemble the current realities of less privileged populations and feature a striking lack of criticality in terms of race, class, and gender [12]. In their "Cheat-Sheet for a Non- (or Less-) Colonialist Speculative Design," they offer 8 steps for recognizing potential problems in one's critical, speculative design [10]. Rather than suggest that every critical design project delve into issues of colonialism explicitly, they offer these questions as a means of supporting self initiated analysis of the power relations one might be replicating in one's own work.

We acknowledge that existing $\mathrm{HCl}$ research might already contend with many of our topics of discussionspecifically structures of oppression, power, and privilege- without explicitly referring to itself as social justice work. Part of the goal of this workshop is to identify and interrogate these practices to be more explicit and deliberate about the role that social justiceand we, as academics-might play in future research. We hope that participants will learn from each other's breadth and depth of experiences, iterating on past strategies and methods to work towards more equitable practices of research and more just contributions to the respective communitiesacademic, political, spatial-with which we engage.

\section{Workshop Goals}

The goal of the workshop is to first and foremost build a community of researchers, practitioners, and organizers around the intersection of technological design and social justice. As stated in our background, there are examples of projects that contend with individual systems of oppression-however, there is presently no unified community or common understanding of how these research projects and activism can hang together. Moreover, there is a clear need to unpack and provide nuanced understandings of $\mathrm{HCl}$ projects that promote "good". Especially given the plurality of definitions and movements representing social justice (and the uptake of technology in such movements), it behooves the $\mathrm{CHI}$ community to support a workshop that seeks to establish such community of inquiry.

Second, we strive to build knowledge together. In our experience with social justice related projects, there are particular questions that need a broad range of experiences and perspectives to help answer. For example: "How can researchers balance commitments to research and the particular activist project at hand?" or "How can different principles of social justice inform $\mathrm{HCl}$ methods, such as decolonization or intersectionality?" In particular, we are interested in building knowledge around design methods, researcher reflexivity, and different epistemic approaches toward design. Just as design is often generative and future looking, so too are social justice endeavors. As the late Grace Lee Boggs, a feminist social activist and 
philosopher, stated, “...we have the power within us to create ourselves and the world anew" [3].

\section{Organizers}

Sarah Fox is a PhD candidate in the Tactile and Tactical (TAT) Design Lab at the University of

Washington. Drawing on feminist theory, design studies, and social work, her research examines reflexive design research methods and how feminist ideas move through technology cultures. Her work has earned a Best Paper award at CSCW. She organized a workshop at Aarhus 2015 and a panel on equity and design at the 2015 Seattle Design Festival.

Mariam Asad is a PhD student in the Digital Media program at Georgia Tech. Her work looks at the sociotechnical structures that support urban advocacy efforts and focuses on ways in which we can better integrate design and community engagement efforts to address local issues of concern. Her work is based out of Atlanta, where she has done research with various communities, local advocacy and activist groups, and city and regional government. Her work has earned an Honorable Mention award at CSCW.

Katherine Lo is a PhD student in the Informatics program at University of California, Irvine. Her research focuses on technology education programs in underserved communities. She currently coordinates diversity and inclusion initiatives for Google and Intel, and runs technology workshops for high school girls in underserved communities throughout California.

Jill Dimond is a maker, scholar, and activist. She is a founder of Sassafras Tech Collective, a worker-owned cooperative focused on the research, design, and development of technologies for social justice. She holds a PhD in Human Centered Computing from Georgia Tech and has a bachelors degree in CS. Her work developing technologies that fight against harassment both online and in the streets has been featured in both scholarly venues and the media such as the New York Times and Washington Post. She has organized many activist workshops including a national Taskforce Against Online Harassment.

Lynn Dombrowski is an Assistant Professor at the School of Informatics and Computing at Indiana University - Purdue University - Indianapolis. Her research focuses applying theories of social justice to her design work by focusing on marginalized communities and social issues like food and labor justice. Her work has earned multiple awards, including a Best Paper at Ubicomp and honorable mentions at $\mathrm{CHI}$ and $\mathrm{CSCW}$.

Shaowen Bardzell is an Associate Professor of Informatics at Indiana University's School of Informatics and Computing. Bardzell's research explores the contributions of design, feminism, and social science to support technology's role in social change. Recent research foci have included emancipatory and participatory social science, criticality in design, care ethics and feminist utopian perspectives for IT, and culture and creative industries in Asia. She is the co-author of Humanistic $\mathrm{HCl}$ (Morgan \& Claypool, 2015) and co-editor of Critical Theory and Interaction Design (MIT Press, in press). She chaired the technical programs at DPPI 2013, DIS2014, and Aarhus 2015 and has organized workshops at CHI, DIS, CSCW, NordiCHI, British HCl, PDC, EPIC, ACE 2007-2015. 


\section{Pre-Workshop Plans}

We will recruit participants via social media and email lists for community organizations in the San Jose area and around the fields of $\mathrm{HCl}$, design, science and technology studies, and information systems. Participants will be selected based on the depth of their position papers in productively engaging with concerns for social justice through design or the thoughtfulness of their critiques.

\section{Workshop Structure}

The aim of this one-day workshop is to share existing research and practice, and to develop new strategies and tools, for designing for social justice in $\mathrm{HCl}$. With this workshop, we build conversations around what it means practically to consider social justice in design. The aim here is to have a discussion about the various approaches that do and could exist to support critical engagement with social justice in $\mathrm{HCl}$ and design. Particularly, with the growing interest amongst practitioners in design for 'good' or social impact, our workshop will scaffold the interrogation and deliberation of key questions though discussions and exercises. These key questions include:

What is the role of $\mathrm{HCl}$ research and practice in working towards social justice? What tools do designers have to make unique contributions towards social justice? How could we better support this work by providing practitioners with the language and tools to address these issues? Conversely, how can we provide tools to researchers with varying levels of engagement with and understanding of doing social justice work?

What are the tensions of being accountable to both an academic community and a field site, and how might those tensions act as challenges or opportunities that we can use to motivate and spur both future research and social change? As academics, it is imperative that we interrogate our own complicities in systems of oppression to be more conscious of how those might factor into our work with community collaborators. Where might there be opportunities to marshal our available resources for design praxis and understand the boundaries of being a good academic and ally?

How do we understand our own limitations as researchers and designers to participate in and understand the spaces in which we are trying to enact social change? Stakeholders often have different ways of making sense of and doing social change. What kind of analytical tools do researchers have to grapple with conflicting ideologies between those working in social justice? How do we as designers and researchers both contend with pressing immediate needs of specific social issues (e.g., hunger, homelessness) and the long work of structural, systemic change? This becomes particular difficult given the limited resources and competing goals and resources to enact social change.

\section{Schedule}

9: 00-10:00 Participant introductions:

Researchers introduce their academic affiliations and briefly explain the role of social justice in their research. Community collaborators briefly describe their work and what they hope to gain from an academic collaboration.

10:00-11:00 I cebreaker activity:

Participants are given a series of prompts to help better interrogate the role of social justice in their research. 
This will be done along various axes: e.g. social justice through methods, through research communities, common challenges in social justice $\mathrm{HCl}$ research, etc. Responses will help align participants along similar interests for the next activity.

11:00-12:30 Breakout groups:

Small groups organize around similar interests based on icebreaker activity responses. Workshop organizers will facilitate conversations among the groups to share common strategies and learn from each other's experiences. This sharing of knowledge will also be documented for purposes beyond the workshop (e.g. an online research portal).

\section{2:30-1:30 Lunch}

1:30-3:30 Field site visit:

Participants will be asked to visit a public commonplace site that is not typically associated with social justice (e.g. grocery store, playground, library). Workshop organizers will provide prompts to encourage participants to interrogate and reframe the site through the lens of social justice, provoking conversations on how we might reframe ongoing research to better orient towards social justice principles. The goals for this activity are to help participants simultaneously defamiliarize and critically examine key concepts associated with design and social justice.

3:30-4:30 Report back

Groups will return to the venue to present their responses to the prompts.

4:30-5:30 Future Steps

Workshop participants and organizers will synthesize the discussions and observations from the day to articulate concrete goals to follow up on after the workshop. This will be contingent on the conversations from the rest of the day, but it can include publications, new research collaborations, or strategies to bring back to their work with their research sites.

\section{5:30-6:00 Closing}

\section{Outcomes}

The primary and long-term goal of the workshop is to build a community of researchers who are committed to social justice through design. Possible long-term outcomes include: research panels and social justicethemed interactive exhibits at $\mathrm{CHI}$ and related conferences and collaborative research projects among workshop participants. We also intend to incorporate discussions from this workshop in a proposal for a special issue of a peer reviewed open access journal like Ada: A Journal of Gender, New Media, and Technology or The Fibreculture J ournal.

After the workshop, discussions and materials will be documented and we will work with attendees to produce a collective annotated bibliography of references mentioned during the event, all hosted on the workshop website. This site will be maintained after the workshop, allowing for participants to continue conversations and collaborations that support future discussion of social justice and design. The website will be hosted on University of Washington servers in order to ensure long-term maintenance and security.

This site can be accessed at the following address: http: //depts. washington.edu/tatlab/socialjustice/ . 


\section{Call for Participation}

As trends toward agendas of design for social change continue to develop, there is a need to move beyond "design with good intentions" toward design praxis or reflection and action directed to transform oppressive structures with and by the dispossessed, marginalized, and oppressed. In this one-day workshop we will share existing research and practice, and to develop new strategies and tools, for designing for social justice in $\mathrm{HCl}$. With this workshop, we will build conversations around what it means practically to consider social justice in design. The aim here is to have a discussion about the various approaches that do and could exist to support critical engagement with social justice in $\mathrm{HCl}$ and design. Topics will include the following: strategies and techniques for social justice research, emphasizing the development of community/academic partnerships, our role as interventionists in research sites, and methods for evaluating and iterating on contributions to our various communities.

We request that participants submit a two to four page thought piece that describes their work in relation to social justice and design. This could take the form of an argument, a portfolio, or an analytic intervention. Submissions will be accepted based on originality, quality, and how well they represent disciplinary and geographic range. Submissions from outside the $\mathrm{HCl}$ community will be particularly welcome (e.g. information studies, anthropology, philosophy, or from community organizations outside of academia).

\section{References}

1. Alison Hope Alkon and Julian Agyeman. 2011. Cultivating Food Justice: Race, Class, and Sustainability. MIT Press.
2. Shaowen Bardzell. 2010. Feminist $\mathrm{HCl}$ : Taking Stock and Outlining an Agenda for Design. Proceedings of the SIGCHI Conference on Human Factors in Computing Systems, ACM, 1301-1310. http://doi.org/10.1145/1753326.1753521

3. James Boggs and Grace Lee Boggs. 1974. Revolution and Evolution. NYU Press.

4. Rachel Clarke, Peter Wright, Madeline Balaam, and John McCarthy. 2013. Digital Portraits: Photosharing After Domestic Violence. Proceedings of the SIGCHI Conference on Human Factors in Computing Systems, ACM, 2517-2526. http://doi.org/10.1145/2470654.2481348

5. Patricia Hill Collins. 2002. Black Feminist Thought: Knowledge, Consciousness, and the Politics of Empowerment. Routledge.

6. Kimberle Crenshaw. 1991. Mapping the Margins: Intersectionality, I dentity Politics, and Violence against Women of Color. Stanford Law Review 43, 6: 1241-1299. http://doi.org/10.2307/1229039

7. Jill P. Dimond, Michaelanne Dye, Daphne Larose, and Amy S. Bruckman. 2013. Hollaback!: The Role of Storytelling Online in a Social Movement Organization. Proceedings of the 2013 Conference on Computer Supported Cooperative Work, ACM, 477490. http://doi.org/10.1145/2441776.2441831

8. Steve Harrison, Phoebe Sengers, and Deborah Tatar. 2011. Making Epistemological Trouble: Thirdparadigm $\mathrm{HCl}$ As Successor Science. Interact. Comput. 23, 5: 385-392. http://doi.org/10.1016/j.intcom.2011.03.005

9. Lilly Irani, Janet Vertesi, Paul Dourish, Kavita Philip, and Rebecca E. Grinter. 2010. Postcolonial

Computing: A Lens on Design and Development. Proceedings of the SIGCHI Conference on Human 
Factors in Computing Systems, ACM, 1311-1320. http://doi.org/10.1145/1753326.1753522 10 Pedro Oliveira and Luiza Prado. 2014. Cheat Sheet for a Non- (or Less-) Colonialist Speculative Design. Medium. Retrieved October 2, 2015 from https://medium.com/a-parede/cheat-sheet-for-anon-or-less-colonialist-speculative-design9a6b4ae3c465

11. Andrea Parker, Vasudhara Kantroo, Hee Rin Lee, Miguel Osornio, Mansi Sharma, and Rebecca Grinter. 2012. Health Promotion As Activism: Building Community Capacity to Effect Social Change. Proceedings of the SIGCHI Conference on Human Factors in Computing Systems, ACM, 99108. http://doi.org/10.1145/2207676.2207692

12. Luiza Prado and Pedro Oliveira. Questioning the "critical" in Speculative \& Critical Design. Medium.
Retrieved July 30, 2015 from

https://medium.com/@luizaprado/questioning-thecritical-in-speculative-critical-design-5a355cac2ca4

13.Jennifer A. Rode. 2011. A Theoretical Agenda for Feminist $\mathrm{HCl}$. Interact. Comput. 23, 5: 393-400. http://doi.org/10.1016/j.intcom.2011.04.005

14. Thomas Smyth and Jill Dimond. 2014. Antioppressive Design. interactions 21, 6: 68-71. http://doi.org/10.1145/2668969

15. Alex S. Taylor. 2011. Out There. Proceedings of the SIGCHI Conference on Human Factors in Computing Systems, ACM, 685-694. http://doi.org/10.1145/1978942.1979042

16. Iris Marion Young. 1990. Justice and the Politics of Difference. Princeton University Press. 